\title{
Three-Dimensional Structure Determination of Surface Sites
}

\author{
Pierrick Berruyer, $^{\dagger}$ Moreno Lelli, $^{\ddagger}$ Matthew P. Conley, ${ }^{\S}, \#$ Daniel L. Silverio, ${ }^{\S}$ Cory M. Widdifield,, \\ Georges Siddiqi, ${ }^{\S}$ David Gajan, ${ }^{\dagger}$ Anne Lesage, ${ }^{*, \dagger}$ Christophe Copéret, ${ }^{*}, \S_{\odot}$ and Lyndon Emsley*, ${ }^{*}$ \\ ${ }^{\dagger}$ Institut des Sciences Analytiques UMR 5280 (CNRS/Université Lyon 1/ENS Lyon), Université de Lyon, Centre de RMN à Très \\ Hauts Champs, 69100 Villeurbanne, France \\ ${ }^{\ddagger}$ Magnetic Resonance Center (CERM), University of Florence, 50019 Sesto Fiorentino (FI), Italy \\ ${ }^{\S}$ Department of Chemistry and Applied Biosciences, ETH Zurich, CH-8037 Zurich, Switzerland \\ "Department of Chemistry, Durham University, DH1 3LE Durham, United Kingdom \\ ${ }^{\perp}$ Institut des Sciences et Ingénierie Chimiques, Ecole Polytechnique Fédérale de Lausanne (EPFL), CH-1015 Lausanne, Switzerland
}

Supporting Information

ABSTRACT: The spatial arrangement of atoms is directly linked to chemical function. A fundamental challenge in surface chemistry and catalysis relates to the determination of three-dimensional structures with atomic-level precision. Here we determine the three-dimensional structure of an organometallic complex on an amorphous silica surface using solidstate NMR measurements, enabled through a dynamic nuclear polarization surface enhanced NMR spectroscopy approach that induces a 200 -fold increase in the NMR sensitivity for the surface species. The result, in combination with EXAFS, is a detailed structure for the surface complex determined with a precision of $0.7 \AA$. We observe a single well-defined conformation that is folded toward the surface in such a way as to include an interaction between the platinum metal center and the surface oxygen atoms.

\section{INTRODUCTION}

Three-dimensional determination of molecules and molecular assemblies from single crystals by diffraction methods has led to today's structure-based understanding of the field. However, if the system under investigation is located on a surface, as in many functional materials, ${ }^{1-5}$ three-dimensional structure determination is largely an unsolved problem.

In fact, it is not even known whether molecular fragments at surfaces form well-defined structures or if they adopt disordered conformations. For example, specific metal-surface interactions have been proposed to be essential in stabilizing active site structures in many heterogeneous catalysts, ${ }^{6-9}$ but so far it has not been possible to obtain three-dimensional structures to confirm such interactions. A range of probes (XPS, EXAFS, STM, etc.) are used to characterize surfaces, but they require either model surfaces under high vacuum or very ordered materials, or they yield only partial descriptions. Nuclear magnetic resonance (NMR) spectroscopy would be an attractive method for determination of surface-supported structures if it were not that the detection limit of NMR under conventional conditions is too low to allow for the study of species at surfaces in many modern materials. This problem has in principle been solved with the introduction of dynamic nuclear polarization (DNP) surface enhanced NMR spectroscopy (SENS), which can increase the NMR signal intensity at

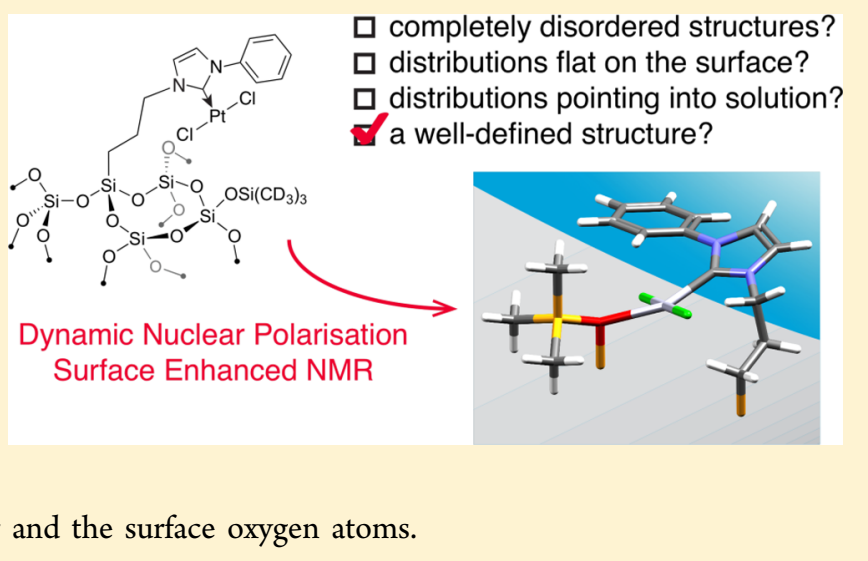

surfaces by an order of magnitude. ${ }^{10-12}$ It has now been applied to record one- and two-dimensional NMR spectra of many systems. ${ }^{13-23}$ Very recently, the introduction of highly efficient polarizing agents, ${ }^{24-26}$ nonaqueous solvents, ${ }^{27}$ and the optimization of sample formulation allows enhancements on the order of 100 to be achieved, which corresponds to a reduction in acquisition times by a factor of 10000 .

Establishing precise quantitative internuclear distances using solid-state NMR methods requires the accurate measurement of the signal decay with respect to moderately long (tens of milliseconds) evolution delays, and is therefore only reliable with high signal-to-noise ratios. Here we determine the threedimensional structure of an organometallic complex supported on an amorphous silica surface. This is achieved through the sensitivity gain provided by DNP SENS enabling the implementation of a series of multidimensional NMR correlation experiments providing structural restraints. The result, in combination with EXAFS, is a detailed structure for the surface complex, determined with a precision of $0.7 \AA$. We observe a single well-defined conformation. Furthermore, the ligand is folded toward the surface in such a way as to include interactions between the coordinated metal and the surface

Received: October 18, 2016

Published: December 20, 2016 
oxygen atoms, thus also illustrating that the surface is not innocent in such hybrid organosilica materials.

\section{EXPERIMENTAL SECTION}

NMR Spectroscopy. DNP SENS experiments were performed using a solid-state DNP-NMR spectrometer made by Bruker BioSpin. It consists of a wide-bore $9.4 \mathrm{~T}$ magnet $\left(\omega_{1 \mathrm{H}} /(2 \pi)=400 \mathrm{MHz}, \omega_{29 \mathrm{Si}} /\right.$ $\left.(2 \pi)=79.5 \mathrm{MHz}, \omega_{13 \mathrm{C}} /(2 \pi)=100.7 \mathrm{MHz}, \omega_{15 \mathrm{~N}} /(2 \pi)=40.6 \mathrm{MHz}\right)$ with a Bruker Avance III HD spectrometer console, and equipped with a triple resonance $3.2 \mathrm{~mm}$ low-temperature CPMAS probe used in the ${ }^{1} \mathrm{H}-{ }^{13} \mathrm{C}-{ }^{15} \mathrm{~N}$ or ${ }^{1} \mathrm{H}-{ }^{29} \mathrm{Si}-{ }^{15} \mathrm{~N}$ configurations with the proper insert. DNP is achieved by irradiating the sample with microwaves at a frequency of $263 \mathrm{GHz}$ which transfers polarization to the ${ }^{1} \mathrm{H}$ nuclei via the cross-effect. ${ }^{28,29}$ The microwaves are generated by a gyrotron and delivered to the sample by a corrugated waveguide with $\approx 22 \mathrm{~W}$ of power reaching the sample. ${ }^{30}$ The microwave power was optimized so as to obtain maximum enhancement for each sample. Sapphire rotors (with zirconia caps) were used for optimal microwave penetration. Rotors are sealed with a Teflon insert to prevent loss of solvent during the measurements.

The REDOR DNP SENS data were acquired with a MAS spinning frequency of $8.0 \mathrm{kHz}$ and sample temperature of approximately $110 \mathrm{~K}$. SPINAL64 ${ }^{1} \mathrm{H}$ heteronuclear decoupling was used with $100 \mathrm{kHz}{ }^{1} \mathrm{H}$ nutation frequencies. ${ }^{31}$

Experimental details for ${ }^{13} \mathrm{C}-\left\{{ }^{15} \mathrm{~N}\right\}$ REDOR experiments on $\mathrm{N}_{1}$ labeled materials can be found Table S3. Tables S4 and S5 lay out experimental parameters for ${ }^{29} \mathrm{Si}-\left\{{ }^{15} \mathrm{~N}\right\}$ REDOR experiments on $\mathbf{A}-\mathbf{N}_{\mathbf{1}}$ and $\mathbf{B}-\mathbf{N}_{\mathbf{1}}$ materials, respectively. Selected REDOR experiments were performed 3 times to establish the reproducibility of ${ }^{29} \mathrm{Si}-\left\{{ }^{15} \mathrm{~N}\right\}$ REDOR with a long dephasing time: twice with the same packed rotors a few months apart (rotors were kept in a $-20^{\circ} \mathrm{C}$ freezer) and a third time with a freshly prepared sample. Experimental details for ${ }^{13} \mathrm{C}$ $\left\{{ }^{15} \mathrm{~N}\right\}$ REDOR and ${ }^{29} \mathrm{Si}-\left\{{ }^{15} \mathrm{~N}\right\}$ REDOR on $\mathrm{N}_{2}$-labeled materials are given in Table S6. Note that, for all experiments, the polarization delay was set to $1.3 \mathrm{~T}_{\mathrm{B}}$, where $\mathrm{T}_{\mathrm{B}}$ is the ${ }^{1} \mathrm{H}$ DNP build-up time measured with a ${ }^{1} \mathrm{H}$ saturation-recovery experiment.

All experimental details for DNP SENS spectroscopy are provided in the SI.

Extended X-ray Absorption Fine Structure (EXAFS). Measurements were carried out at the $\mathrm{Pt} \mathrm{L}_{3}$ edge at the SuperXAS beamline at SLS (PSI, Villigen, Switzerland). The storage ring was operated at 2.4 $\mathrm{GeV}$ in top-up mode with a ring current of around $400 \mathrm{~mA}$. The incident photon beam provided by a $2.9 \mathrm{~T}$ super bend magnet source was selected by a $\mathrm{Si}$ (111) quick-EXAFS monochromator and the rejection of higher harmonics and focusing were achieved by a rhodium-coated collimating mirror at $2.8 \mathrm{mrad}$ and a rhodium-coated torroidal mirror at $2.8 \mathrm{mrad}$. The beam size on the sample was $100 \times$ $100 \mu \mathrm{m}^{2}$. During the measurements, the monochromator was rotating with $10 \mathrm{~Hz}$ frequency in $2^{\circ}$ angular range, and X-ray absorption spectra were collected in transmission mode using ionization chambers specially developed for quick data collection with $1 \mathrm{MHz}$ frequency. ${ }^{32}$ The beamline energy was calibrated with Pt reference foil to the $\mathrm{Pt} \mathrm{L}_{3}$ edge position at $11564.0 \mathrm{eV}$. To avoid contact with air all samples were sealed in a glovebox. Each sample pellet (with optimized thickness for transmission detection) was placed in two aluminized plastic bags (polyaniline $(15 \mu \mathrm{m})$, polyethylene $(15 \mu \mathrm{m}), \mathrm{Al}(12 \mu \mathrm{m})$, polyethylene $(75 \mu \mathrm{m})$ from Gruber-Folien $\mathrm{GmbH}$ \& Co. $\mathrm{KG}$, Straubing, Germany) using an impulse sealer inside a glovebox; one sealing layer was removed immediately before the measurements. ${ }^{33}$ Data were analyzed by standard procedures using the Ifeffit program package. ${ }^{34,35}$

Computation for the Structure Determination Procedure. Calculations were performed using MathWorks Matlab software (versions R2014B or R2016A). The processed TopSpin NMR data were imported into MatLab with the ReadBruker2D script developed by the National Magnetic Resonance Facility at Madison (NMRFAM) of the University of Wisconsin-Madison, published under the GNU General Public License v3. Deconvolution was performed using the peakfit v2.0 MatLab script available on the MathWorks File Exchange platform under BSD license.

Computational Modeling under Density Functional Theory. All DFT modeling was performed with the Amsterdam Density Functional (ADF) software suite, version 2014.10. ${ }^{36,37}$ The experimentally determined structure of precatalyst $\mathbf{A}$ was anchored on the realistic amorphous silica surface model suggested previously by Ugliengo et al. ${ }^{38}$ To roughly approximate the degree of surface hydroxylation and the desired $\mathrm{Si}-\mathrm{Si}$ distance of ca. $4.5 \AA$, the surface model having $5.4 \mathrm{OH} \mathrm{nm}^{-2}$ was chosen (coordinates provided in $\mathrm{SI}$ ). Due to the size of the fragments anchored on the silica surface model, periodic codes were not chosen as it was seen that prohibitively large unit cell volumes (ca. $9000 \AA^{3}$ ) would be required to ensure no overlap between these fragments in adjacent cells. As such, a discrete silica model cluster was selected having a diameter of roughly $10 \AA$, to which A was then anchored. All dangling oxygen atoms were terminated with hydrogen atoms, leading to the starting cluster pictured in Figure S12, with the coordinates being provided in the SI. While efforts were made to ensure that the geometry of the individual components (A and TMS) matched with that determined from the experimental NMR data, due to the nature of the amorphous silica surface model, there was a small difference in the relative orientation between $\mathbf{A}$ and the TMS fragment.

In all cases, DFT calculations were performed at the generalized gradient approximation (GGA) level of theory using the exchangecorrelation functional of Perdew, Burke, and Ernzerhof (PBE). ${ }^{3,40}$ Dispersion effects were included by the three parameter correction presented by Grimme and co-workers. ${ }^{41}$ Relativistic effects were included at the scalar level during all computations under the zerothorder regular approximation (ZORA). ${ }^{42-44}$ Due to the large nature of the cluster, the geometry optimization portion of the calculation used frozen core basis sets (except hydrogen) which were triple- $\zeta$ in the valence region ("TZP" according to the ADF naming scheme). This was specified by setting the parameter "core" equal to "medium" in the input file, which translates into the following: $\mathrm{C}$ (1s frozen), $\mathrm{O}$ (1s frozen), $\mathrm{N}$ (1s frozen), $\mathrm{Si}$ (up to $2 \mathrm{p}$ frozen), $\mathrm{Cl}$ (up to $2 \mathrm{p}$ frozen). Effects due to solvation by 1,1,2,2-tetrachloroethane were included using the conductor-like screening model (COSMO) $)^{45,46}$ by using the following string in the "Solvation" block of the input file: "Solv Eps = $8.42 \mathrm{Rad}=3.15$ ". The final optimized geometry is provided in Figure S13 (coordinates given in separate file of the SI), and a comparison between the final DFT-optimized geometry with that determined experimentally is given in Figure S14.

Synthesis of the Materials. All the details regarding materials synthesis are given in the SI.

Synthesis of the Polarizing Agent. TEKPol2 was provided by Prof. Paul Tordo and Dr. Olivier Ouari (Aix-Marseille University) and prepared according to the synthesis previously reported. ${ }^{26}$

\section{RESULTS AND DISCUSSION}

The surface Pt-complex B studied here (Figure 1) was used as a representative surface site. $\mathbf{B}$ belongs to a broad family of metalbased hybrid catalytic materials where metal-surface interactions are thought to be important for function. ${ }^{6-9}$ The precursor A (Figure 1) is an example of a supported ligand, closely related to ionic liquid phases (SILP), which is a class of systems attracting large current interest. ${ }^{47,48} \mathbf{A}$ was synthesized via a sol-gel method in the presence of a structure directing agent ${ }^{49}$ to obtain a random distribution of organic units within the hexagonal arrangement of cylindrical pores in the material. ${ }^{50}$ Post modification of $\mathbf{A}$ with $\left(\mathrm{CD}_{3}\right)_{3} \mathrm{SiCl}$ (vide infra) and derivatization of the imidazolium unit with $\mathrm{Pt}(\mathrm{II})$ yields B, see Supporting Information. Both materials have been synthesized with ${ }^{15} \mathrm{~N}$-labels at two different positions: $\mathbf{A} / \mathbf{B}-\mathbf{N}_{1}$ represents material $\mathbf{A} / \mathbf{B}$ with ${ }^{15} \mathrm{~N}$-labeling at $\mathrm{N}_{1}$, whereas $\mathbf{A} / \mathbf{B}$ $\mathbf{N}_{2}$ is A or B with ${ }^{15} \mathrm{~N}$-labeling at site $\mathrm{N}_{2}$. The concentration of 

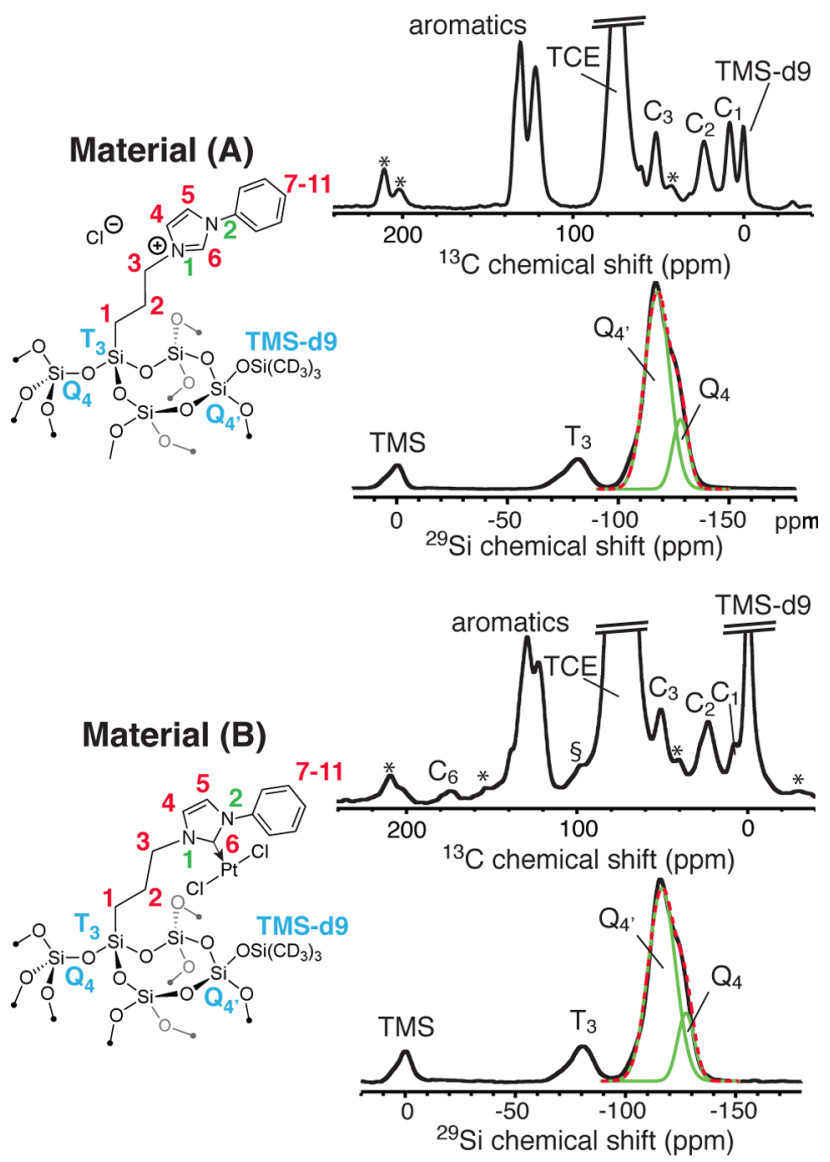

Figure 1. Chemical structure and NMR signal assignments. Left: the chemical structure of material A together with the ${ }^{13} \mathrm{C}$ and ${ }^{29} \mathrm{Si}$ CPMAS DNP SENS spectra for A-N $\mathbf{N}_{1}$. Right: the same for material $\mathbf{B}$. Symbol * denotes spinning side bands, and $\S$ denotes pentachloroethane impurity found in commercial 1,1,2,2 tetra-chloroethane used as the impregnating solvent (see Supporting Information Figure S7 for details). For the ${ }^{29} \mathrm{Si}$ spectra, the deconvolution of the $\mathrm{Si}_{\mathrm{Q}_{4}} / \mathrm{Si}_{\mathrm{Q}^{\prime}}$ peaks is shown, where the component Gaussian peaks are drawn with solid green lines and the sum is drawn with a dashed red line.

active surface species is about $0.2 \mathrm{~nm}^{-2}$ for the materials studied here.

To obtain a signal-to-noise ratio that is as high as possible and thus precise quantitative information on the sample from solid-state NMR, sample preparation for DNP must be done carefully. Sample formulation was optimized to yield the highest sensitivity in DNP SENS experiments. Samples were prepared by impregnating $15 \mathrm{mg}$ of the powdered material with $17 \mu \mathrm{L}$ of a $16 \mathrm{mM}$ solution of TEKPol $2^{26}$ in $1,1,2,2$ tetrachloroethane (TCE), ${ }^{27}$ and then packed into a $3.2 \mathrm{~mm}$ sapphire rotor sealed with a Teflon insert and a zirconia cap. TEKPol2 is the best performing polarizing agent reported to date in nonaqueous solvents at $9.4 \mathrm{~T}$ and around $110 \mathrm{~K} .{ }^{26} \mathrm{DNP}$ SENS enhancements are linked to ${ }^{1} \mathrm{H}$ spin-lattice relaxation times, and surface passivating groups containing methyl moieties can lead to rapid ${ }^{1} \mathrm{H}$ spin-lattice relaxation and therefore poor signal enhancements. The materials used here were thus passivated with deuterated trimethysilyl group (TMS- $d_{9}$ ) since deuteration yields long relaxation times and concomitant high enhancements. ${ }^{51}$ Finally, samples were degassed to reduce relaxation due to dissolved $\mathrm{O}_{2} .{ }^{52}$ With this protocol, the enhancement of the solvent was $\varepsilon_{\mathrm{H}}=213$ for A and $\varepsilon_{\mathrm{H}}=200$ for $\mathbf{B}$, which is the highest value obtained so far

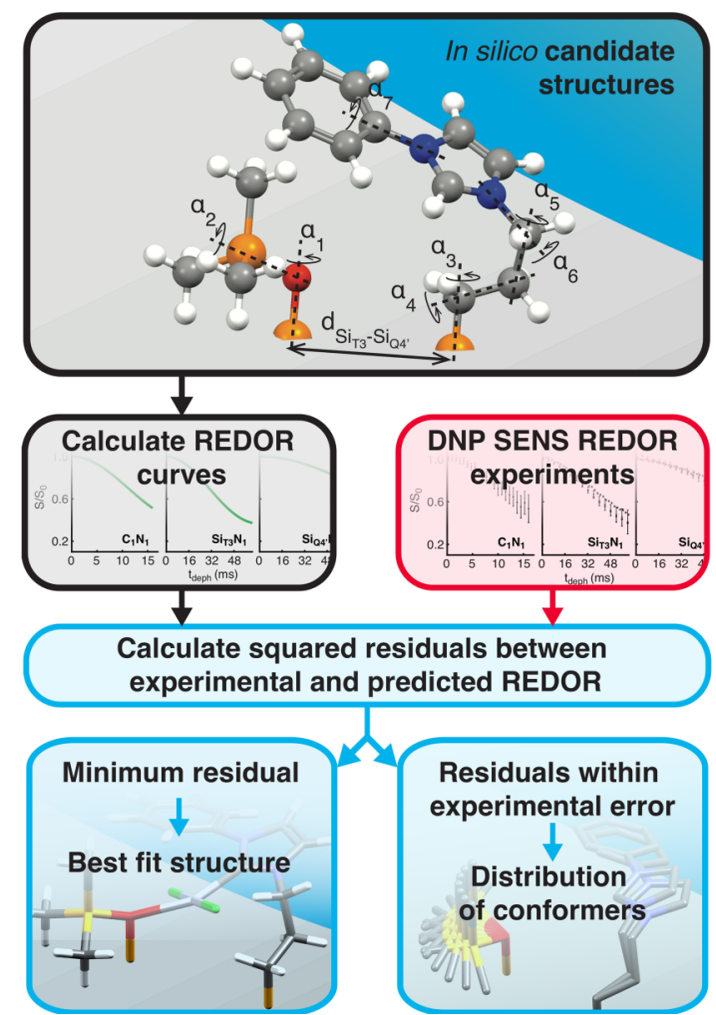

Figure 2. Three-dimensional structure determination. Possible 3D structures for the system were generated in silico, as visualized here with a simple "ball and stick" model, by rotating atoms around the 4 axes $\left(\alpha_{1}, \alpha_{3}, \alpha_{4}\right.$, and $\left.\alpha_{5}\right)$ in $15^{\circ}$ steps for each of the four selected $\mathrm{Si}_{\mathrm{T} 3}-$ $\mathrm{Si}_{\mathrm{Q}^{\prime}}$ distances. Analytical REDOR curves were then calculated for each structure and compared to the ensemble of experimental REDOR curves to determine (i) the single $3 \mathrm{D}$ structure in best agreement with the experimental data, and (ii) the distribution of conformers that agree with the data to within the estimated experimental error.

for an impregnated materials sample, and which enables experiments that were not possible before.

Figure 1 shows the resulting ${ }^{13} \mathrm{C}$ and ${ }^{29} \mathrm{Si}$ DNP SENS crosspolarization magic angle spinning (CPMAS) NMR spectra for A- $\mathbf{N}_{1}$. The ${ }^{13} \mathrm{C}$ NMR spectrum contains sufficiently wellresolved signals to assign the three alkyl carbons, and the TMS groups. Similarly, $\mathrm{Si}_{\mathrm{TMS}}$ and $\mathrm{Si}_{\mathrm{T} 3}$ can be easily assigned in the ${ }^{29} \mathrm{Si}$ NMR spectra. Discrimination between $\mathrm{Si}_{\mathrm{Q}_{4}}$ and $\mathrm{Si}_{\mathrm{Q}^{\prime}}$ signals is possible by deconvolution of the broad Q-site peak and by assignment of the two overlapping signals with a DNP SENS ${ }^{29} \mathrm{Si}-{ }^{29} \mathrm{Si}$ refocused two-dimensional INADEQUATE at natural isotopic abundance (Figure $\mathrm{S} 1)^{53}$ The spectra of $\mathbf{B}$ (Figure 1) are similar to those of $\mathbf{A}$, with an extra ${ }^{13} \mathrm{C}$ signal at $173 \mathrm{ppm}$, which was assigned to the $\mathrm{C}_{6}$ carbene signal using a ${ }^{1} \mathrm{H}-{ }^{15} \mathrm{~N}-{ }^{13} \mathrm{C}$ double CP DNP SENS experiment (Figure S7). Two-dimensional ${ }^{1} \mathrm{H}-{ }^{13} \mathrm{C}$ and ${ }^{1} \mathrm{H}-{ }^{29} \mathrm{Si}$ heteronuclear correlation (HETCOR) experiments on $\mathbf{A}-\mathbf{N}_{\mathbf{1}}$ and $\mathbf{B}-\mathbf{N}_{\mathbf{1}}$ confirm the assignment of the resolved resonances and provide access to the corresponding ${ }^{1} \mathrm{H}$ chemical shifts (Figures S3-S6).

Structural constraints were obtained from DNP SENS ${ }^{13} \mathrm{C}$ $\left\{{ }^{15} \mathrm{~N}\right\}$ and ${ }^{29} \mathrm{Si}-\left\{{ }^{15} \mathrm{~N}\right\}$ rotational echo double resonance (REDOR) experiments ${ }^{54,55}$ on the ${ }^{15} \mathrm{~N}$-labeled samples. Modulation of the ${ }^{13} \mathrm{C}$ and ${ }^{29} \mathrm{Si}$ signal intensity as a function of the ${ }^{15} \mathrm{~N}$ recoupling time is characteristic of the distance between isolated spin pairs. For each compound, 12 REDOR curves were measured. Fits of the four $\mathrm{C}_{3}-\mathrm{N}_{i}$ and $\mathrm{C}_{2}-\mathrm{N}_{i}(i=1$ 


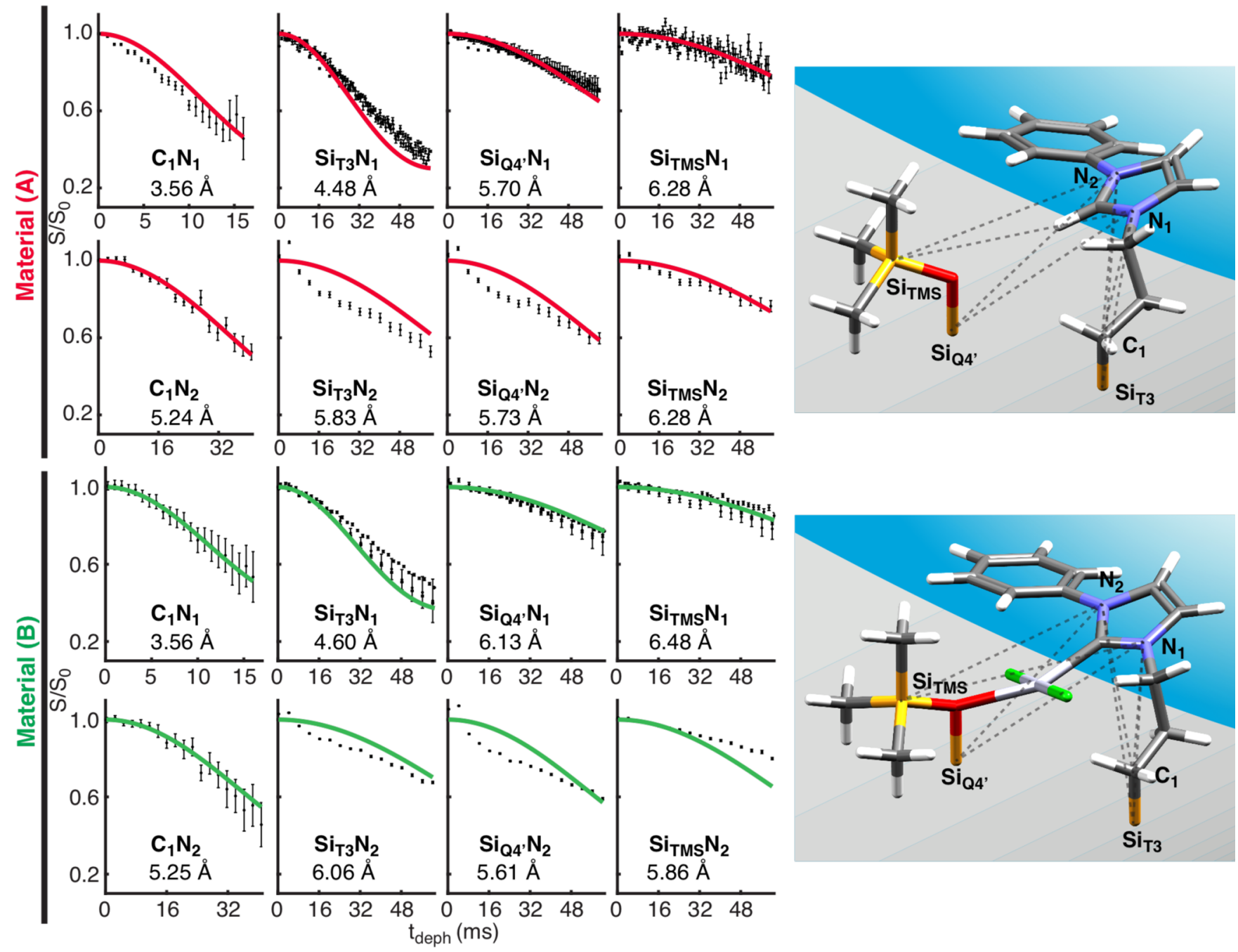

Figure 3. Three-dimensional structures of materials A and B. The experimental DNP SENS REDOR data are shown on the left for A (above) and for the Pt-complex B (below) with black dots for the 8 different spin pairs which generate nontrivial constraints. The solid red and green lines are the calculated REDOR curves for the structures in best agreement with the experimental data. The internuclear distances for each spin pair in the structure in best agreement with the experimental data are reported for each curve. The corresponding best fit structures are shown on the right, and coordinates are given in the SI. The dashed lines shown on the structures correspond to the REDOR constraints used for structure determination.

or 2) curves yielded distances in agreement with canonical values for the covalent geometry (Figures S9 and S10). The remaining eight $\mathrm{C}_{1}-\mathrm{N}_{i}, \mathrm{Si}_{\mathrm{TMS}}-\mathrm{N}_{i}, \mathrm{Si}_{\mathrm{Q}^{\prime}}-\mathrm{N}_{i}$, and $\mathrm{Si}_{\mathrm{T} 3}-\mathrm{N}_{i}$ (with $i=1$ or 2 ) curves provided nontrivial structural information used in the 3D structure determination.

Structure Determination Procedure. The three-dimensional structure of the organometallic complex was determined with a method analogous to that routinely used for NMR protein structure determination, where the covalent geometry is assumed and only the conformational degrees of freedom are varied in order to find the best agreement with the ensemble of experimental constraints. The whole surface-structure determination process is outlined in Figure 2 and detailed in the SI. For surface complexes, the number of conformational degrees of freedom is often relatively limited, and we can envisage a systematic search of all possible conformers. The conformational degrees of freedom are the seven torsion angles (noted as $\alpha_{1}, \alpha_{2}, \alpha_{3}, \alpha_{4}, \alpha_{5}, \alpha_{6}$, and $\alpha_{7}$ in Figure 2), and the distance between the $\mathrm{Si}_{\mathrm{T} 3}$ and $\mathrm{Si}_{\mathrm{Q}^{\prime}}$ atoms $\left(d_{\mathrm{SiT}_{3}-\mathrm{SiQ}_{4}}\right)$. The rotation around $\alpha_{2}$ within the TMS group is set to an arbitrary value since a low barrier to rotation is expected, and hence, a distribution of conformers should be present (as for the methyl groups themselves). Note that due to the nature of the silica surface, the distance $d_{\mathrm{SiT} 3-\mathrm{SiQ}_{4}}$ can only take discrete values. The best fit structures determined in this way are shown in Figure 3, along with the 8 corresponding REDOR curves superimposed on the experimental data for A (top) and B (bottom). To assess the reliability of the structures, the reproducibility of the experimental data was verified by performing the DNP SENS $\mathrm{Si}-\left\{{ }^{15} \mathrm{~N}\right\}$ REDOR experiments for $\mathbf{A}-\mathbf{N}_{\mathbf{1}}$ and $\mathbf{B}-\mathbf{N}_{\mathbf{1}}$ in triplicate. All data were consistent within error, and the ensemble of data was used for the final structure determination.

Since we do not have any experimental NMR constraints on the torsion angle around the $\mathrm{N}_{1}-\mathrm{C}_{3}$ axis $\left(\alpha_{6}\right)$, this orientation was determined using the $\mathrm{Pt}-\mathrm{O}$ distance obtained from EXAFS analysis of $\mathbf{B}$ which, depending on the model used, suggests a $\mathrm{Pt}-\mathrm{O}$ distance of approximately $2.68 \AA$ (Figure S16 and Table S8 of the SI are providing details of the EXAFS data analysis). The structure therefore strongly suggests the presence of stabilizing noncovalent interactions between Pt and the oxygen atom of the trimethylsiloxy group. The analysis of the EXAFS data also provided the $\mathrm{Pt}-\mathrm{C}$ and $\mathrm{Pt}-\mathrm{Cl}$ distances which are 


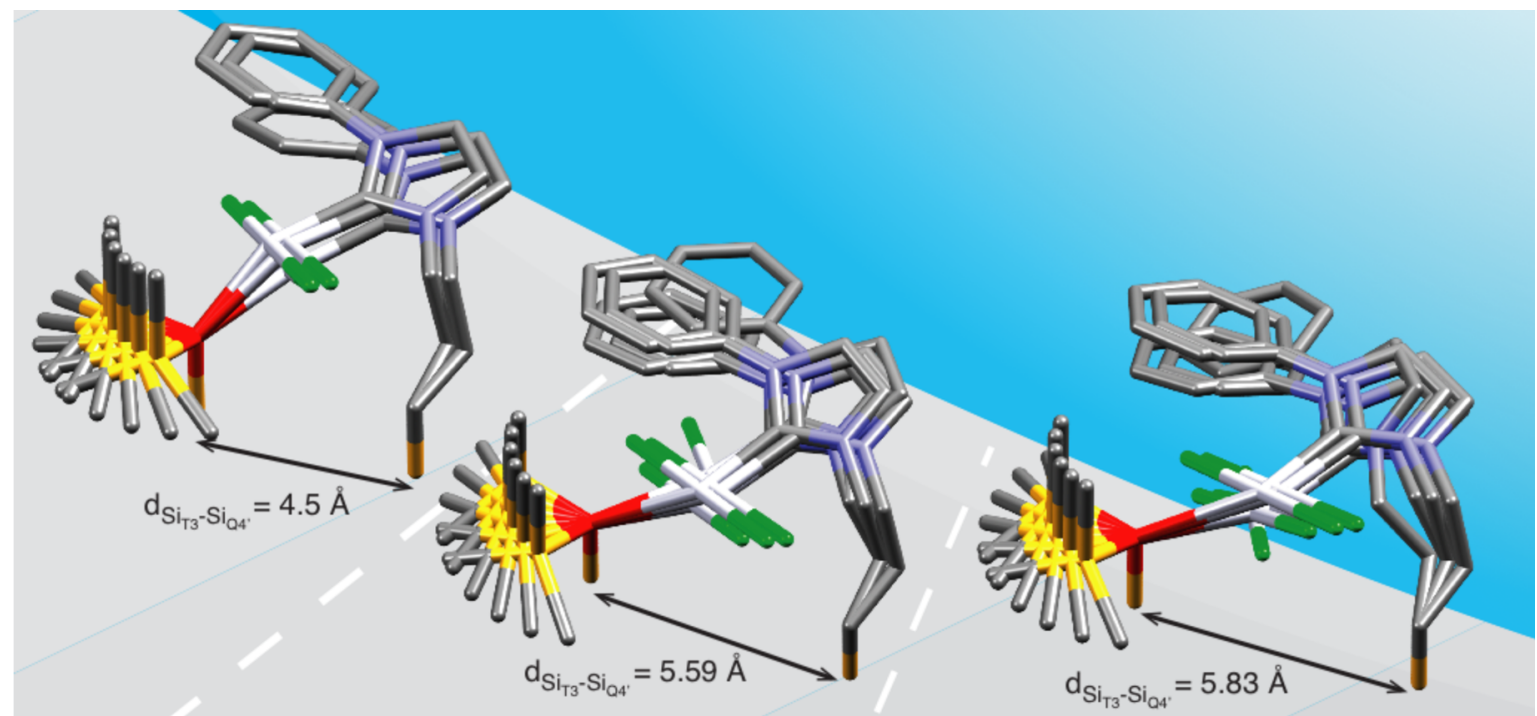

Figure 4. Ensemble of conformers for the Pt-complex B. There are 14 structures of $\mathbf{B}$ with $d_{\mathrm{SiT3}-\mathrm{SiQ} 4^{\prime}}=4.50 \AA$, 25 with $d_{\mathrm{SiT3}-\mathrm{SiQ} 4^{\prime}}=5.59 \AA$, and 23 with $d_{\mathrm{SiT} 3-\mathrm{SiQ} 4^{\prime}}=5.83 \AA$ shown. The RMSD among the ensemble is $0.62 \AA$ for $d_{\mathrm{SiT3}-\mathrm{SiQ} 4^{\prime}}=4.50 \AA, 0.71 \AA$ for $d_{\mathrm{SiT}^{-} \mathrm{SiQ} 4^{\prime}}=5.59 \AA$, and $0.70 \AA$ for $d_{\mathrm{SiT3}_{-} \mathrm{SiQ}_{4^{\prime}}}=5.83 \AA$. The structures are superimposed by aligning $\mathrm{Si}_{\mathrm{T} 3}, \mathrm{Si}_{\mathrm{Q}^{\prime}}$, and $\mathrm{O}$.

consistent with values obtained from the CSD. The same $\alpha_{6}$ value was used for A for display purposes.

Structure Verification with a DFT Computational Approach. A density functional theory (DFT) geometry optimization, starting from the experimentally determined structure of A, finds the experimentally determined structure is largely retained (Figure S14 compares the experimentally determined structure and the DFT optimized one), increasing confidence in the result, with an RMSD between the experimentally determined and the DFT optimized structure of only $0.69 \AA$ (i.e., within our stated uncertainty). Furthermore, a calculation of the NMR chemical shift was performed. The agreement between the calculated and experimental chemical shifts is reasonable.

Definition of an Ensemble of Conformation within Experimental Error. Cross-validation was used to estimate the uncertainty on the final structure. Figure 4 shows the ensemble of structures for material $\mathbf{B}$ that are within the uncertainty of the measurements. Note that no structures were found for $\mathbf{B}$ which are compatible with the shortest $d_{\mathrm{SiT3} 3 \mathrm{SiQ}^{\prime}}$ distance of $3.17 \AA$. For each of the values of $d_{\mathrm{SiT3}-\mathrm{SiQ} 4^{\prime}}$, the structures remain otherwise qualitatively very similar; i.e., the key features of the structures do not actually change much with variations in $d_{\mathrm{SiT3}-\mathrm{SiQ} 4}$, and so the choice of the silica surface model does not appear to be critically important in determining the structure. As shown in Figure 4, the distribution of possible structures is small. The RMSD (including the non-H atoms in the tether and the two nitrogen atoms) among of the ensemble is $0.62 \AA$ for $d_{\mathrm{SiT3}^{-} \mathrm{SiQ} 4^{\prime}}=4.50 \AA, 0.71 \AA$ for $d_{{\mathrm{SiT} 3-\mathrm{SiQ} 4^{\prime}}^{\prime}}=5.59$, and $0.70 \AA$ for $d_{\mathrm{SiT} 3-\mathrm{SiQ} 4^{\prime}}=5.83 \AA$, indicating that the structures are well-constrained by the data.

In these structures we observe first that the complex adopts a single well-defined conformation on the surface, and that the flexible tether allows the organic moieties to fold toward the silica surface, suggesting stabilizing interactions between the silica surface and the aromatic groups. The $\mathrm{N}_{1}$ and $\mathrm{N}_{2}$ distances to the surface (defined as the plane perpendicular to the plane spanned by the $\mathrm{Si}_{\mathrm{T} 3}-\mathrm{C}_{1}$ vector) are 3.64 and $3.82 \AA$ in $\mathbf{B}$ (whereas the van der Waals radius would be $1.50 \AA$ and the distances in a fully extended conformation perpendicular to the surface would be 4.16 and $6.16 \AA$ ).

Importantly, our results do allow for the possibility of a distribution of structures, and yet, interestingly, as seen in Figure 4 , for all the different values of $d_{\mathrm{SiT3}-\mathrm{SiQ}_{4} \text {, the }}$ conformation of the organic fragment in $\mathbf{B}$ determined experimentally is well-defined and very similar: folded toward the surface, with a structure such that the $\mathrm{C}-\mathrm{Pt}-\mathrm{O}$ interaction is roughly constant.

The structure ensemble has also been investigated for material $\mathbf{A}$ and the ensemble of conformers provided in Figure S34. We also found that the organic fragment in $\mathbf{A}$ is welldefined.

\section{CONCLUSION}

In summary, using dynamic nuclear polarization surface enhanced multidimensional NMR methods, we have been able to obtain multiple structural constraints that allow us, in combination with EXAFS, to directly determine the threedimensional structure of a surface species with an average RMSD in the positions of the ligand of $0.71 \AA$. The result shows a single well-defined structure, which is not significantly disordered. Additionally, the ligand conformation is determined to be folded toward the silica surface, with interactions between the coordinated metal and surface oxygen sites, thus illustrating that the surface is not innocent in such hybrid organosilica materials. This information corroborates several previously published results, ${ }^{6,7,50}$ which suggested that metal-surface interactions existed and are important to stabilize active species in immobilized catalysts. The approach developed here demonstrates quantitatively the existence of such interactions on an immobilized $\mathrm{Pt}-\mathrm{NHC}$ surface species used as a prototypical surface site. Surface-structure determination is expected to guide the future design of immobilized catalysts, by directly exploiting interactions with the support. 


\section{ASSOCIATED CONTENT}

\section{S Supporting Information}

The Supporting Information is available free of charge on the ACS Publications website at DOI: 10.1021/jacs.6b10894.

Structure coordinate files (ZIP)

Supplementary experimental details, and material characterization and methods (PDF)

\section{AUTHOR INFORMATION}

\section{Corresponding Authors}

*anne.lesage@ens-lyon.fr

*ccoperet@ethz.ch

*lyndon.emsley@epfl.ch

\section{ORCID}

Christophe Copéret: 0000-0001-9660-3890

Lyndon Emsley: 0000-0003-1360-2572

\section{Present Address}

\# Department of Chemistry, University of California, Riverside, California 92521, United States.

\section{Notes}

The authors declare no competing financial interest.

\section{ACKNOWLEDGMENTS}

Financial support is acknowledged from the ERC Advanced Grant No. 320860. Lénaïc Leroux is acknowledged for technical assistance at the CRMN. Prof. Paul Tordo and Dr. Olivier Ouari are thanked for providing TEKPol2.

\section{REFERENCES}

(1) Tsubogo, T.; Oyamada, H.; Kobayashi, S. Nature 2015, 520, 329-332.

(2) Fu, Q.; Li, W.-X.; Yao, Y.; Liu, H.; Su, H.-Y.; Ma, D.; Gu, X.-K.; Chen, L.; Wang, Z.; Zhang, H.; Wang, B.; Bao, X. Science 2010, 328, 1141-1144.

(3) Kim, Y.; Macfarlane, R. J.; Jones, M. R.; Mirkin, C. A. Science 2016, 351, 579-582.

(4) Blanc, F.; Berthoud, R.; Coperet, C.; Lesage, A.; Emsley, L.; Singh, R.; Kreickmann, T.; Schrock, R. R. Proc. Natl. Acad. Sci. U. S. A. 2008, 105, 12123-12127.

(5) Hughes, M. D.; Xu, Y.-J.; Jenkins, P.; McMorn, P.; Landon, P.; Enache, D. I.; Carley, A. F.; Attard, G. a; Hutchings, G. J.; King, F.; Stitt, E. H.; Johnston, P.; Griffin, K.; Kiely, C. J. Nature 2005, 437, $1132-1135$

(6) Samantaray, M. K.; Alauzun, J.; Gajan, D.; Kavitake, S.; Mehdi, A.; Veyre, L.; Lelli, M.; Lesage, A.; Emsley, L.; Copéret, C.; Thieuleux, C. J. Am. Chem. Soc. 2013, 135, 3193-3199.

(7) Romanenko, I.; Gajan, D.; Sayah, R.; Crozet, D.; Jeanneau, E.; Lucas, C.; Leroux, L.; Veyre, L.; Lesage, A.; Emsley, L.; Lacôte, E.; Thieuleux, C. Angew. Chem., Int. Ed. 2015, 54, 12937-12941.

(8) Stalzer, M. M.; Delferro, M.; Marks, T. J. Catal. Lett. 2015, 145, $3-14$.

(9) Van Berlo, B.; Houthoofd, K.; Sels, B. F.; Jacobs, P. A. Adv. Synth. Catal. 2008, 350, 1949-1953.

(10) Lesage, A.; Lelli, M.; Gajan, D.; Caporini, M. a; Vitzthum, V.; Miéville, P.; Alauzun, J.; Roussey, A.; Thieuleux, C.; Mehdi, A.; Bodenhausen, G.; Copéret, C.; Emsley, L. J. Am. Chem. Soc. 2010, 132, 15459-15461.

(11) Lelli, M.; Gajan, D.; Lesage, A.; Caporini, M. A.; Vitzthum, V.; Mi, P.; Rasc, F.; Roussey, A.; Boualleg, M.; Veyre, L.; Emsley, L.; et al. J. Am. Chem. Soc. 2011, 133, 2104-2107.

(12) Rossini, A. J.; Zagdoun, A.; Lelli, M.; Lesage, A.; Copéret, C.; Emsley, L. Acc. Chem. Res. 2013, 46, 1942-1951.

(13) Ong, T. C.; Liao, W. C.; Mougel, V.; Gajan, D.; Lesage, A.; Emsley, L.; Copéret, C. Angew. Chem., Int. Ed. 2016, 55, 4743-4747.
(14) Lilly Thankamony, A. S.; Lion, C.; Pourpoint, F.; Singh, B.; Perez Linde, A. J.; Carnevale, D.; Bodenhausen, G.; Vezin, H.; Lafon, O.; Polshettiwar, V. Angew. Chem., Int. Ed. 2015, 54, 2190-2193.

(15) Mouat, A. R.; George, C.; Kobayashi, T.; Pruski, M.; van Duyne, R. P.; Marks, T. J.; Stair, P. C. Angew. Chem., Int. Ed. 2015, 54, 1334613351.

(16) Wolf, P.; Valla, M.; Rossini, A. J.; Comas-Vives, A.; NúñezZarur, F.; Malaman, B.; Lesage, A.; Emsley, L.; Copéret, C.; Hermans, I. Angew. Chem., Int. Ed. 2014, 53, 10179-10183.

(17) Sangodkar, R. P.; Smith, B. J.; Gajan, D.; Rossini, A. J.; Roberts, L. R.; Funkhouser, G. P.; Lesage, A.; Emsley, L.; Chmelka, B. F. J. Am. Chem. Soc. 2015, 137, 8096-8112.

(18) Rossini, A. J.; Zagdoun, A.; Lelli, M.; Canivet, J.; Aguado, S.; Ouari, O.; Tordo, P.; Rosay, M.; Maas, W. E.; Copéret, C.; Farrusseng, D.; Emsley, L.; Lesage, A. Angew. Chem., Int. Ed. 2012, 51, 123-127.

(19) Blanc, F.; Sperrin, L.; Lee, D.; Dervişoğlu, R.; Yamazaki, Y.; Haile, S. M.; De Paëpe, G.; Grey, C. P. J. Phys. Chem. Lett. 2014, 5, 2431-2436.

(20) Rossini, A. J.; Zagdoun, A.; Hegner, F.; Schwarzwälder, M.; Gajan, D.; Copéret, C.; Lesage, A.; Emsley, L. J. Am. Chem. Soc. 2012, 134, 16899-16908.

(21) Märker, K.; Pingret, M.; Mouesca, J. M.; Gasparutto, D.; Hediger, S.; De Paëpe, G. J. Am. Chem. Soc. 2015, 137, 13796-13799.

(22) Mollica, G.; Dekhil, M.; Ziarelli, F.; Thureau, P.; Viel, S. Angew. Chem., Int. Ed. 2015, 54, 6028-6031.

(23) Protesescu, L.; Rossini, A. J.; Kriegner, D.; Valla, M.; de Kergommeaux, A.; Walter, M.; Kravchyk, K. V.; Nachtegaal, M.; Stangl, J.; Malaman, B.; Reiss, P.; Lesage, A.; Emsley, L.; Copéret, C.; Kovalenko, M. V. ACS Nano 2014, 8, 2639-2648.

(24) Zagdoun, A.; Casano, G.; Ouari, O.; Schwarzwälder, M.; Rossini, A. J.; Aussenac, F.; Yulikov, M.; Jeschke, G.; Copéret, C.; Lesage, A.; Tordo, P.; Emsley, L. J. Am. Chem. Soc. 2013, 135, 12790-12797.

(25) Sauvée, C.; Rosay, M.; Casano, G.; Aussenac, F.; Weber, R. T.; Ouari, O.; Tordo, P. Angew. Chem., Int. Ed. 2013, 52, 10858-10861.

(26) Kubicki, D. J.; Casano, G.; Schwarzwälder, M.; Abel, S.; Sauvée, C.; Ganesan, K.; Yulikov, M.; Rossini, A. J.; Jeschke, G.; Copéret, C.; Lesage, A.; Tordo, P.; Ouari, O.; Emsley, L. Chem. Sci. 2016, 7, 550558.

(27) Zagdoun, A.; Rossini, A. J.; Gajan, D.; Bourdolle, A.; Ouari, O.; Rosay, M.; Maas, W. E.; Tordo, P.; Lelli, M.; Emsley, L.; Lesage, A.; Copéret, C. Chem. Commun. 2012, 48, 654-656.

(28) Maly, T.; Debelouchina, G. T.; Bajaj, V. S.; Hu, K.-N.; Joo, C.G.; Mak-Jurkauskas, M. L.; Sirigiri, J. R.; van der Wel, P. C. a; Herzfeld, J.; Temkin, R. J.; Griffin, R. G. J. Chem. Phys. 2008, 128, 052211.

(29) Matsuki, Y.; Maly, T.; Ouari, O.; Karoui, H.; Le Moigne, F.; Rizzato, E.; Lyubenova, S.; Herzfeld, J.; Prisner, T.; Tordo, P.; Griffin, R. G. Angew. Chem., Int. Ed. 2009, 48, 4996-5000.

(30) Rosay, M.; Tometich, L.; Pawsey, S.; Bader, R.; Schauwecker, R.; Blank, M.; Borchard, P. M.; Cauffman, S. R.; Felch, K. L.; Weber, R. T.; Temkin, R. J.; Griffin, R. G.; Maas, W. E. Phys. Chem. Chem. Phys. 2010, 12, 5850-5860.

(31) Fung, B. M.; Khitrin, A. K.; Ermolaev, K. J. Magn. Reson. 2000, 142, 97-101.

(32) Müller, O.; Stötzel, J.; Lützenkirchen-Hecht, D.; Frahm, R. J. Phys.: Conf. Ser. 2013, 425, 092010.

(33) Koningsberger, D. C.; Prins, R. X-ray Absorption: Principles, Applications, Techniques of EXAFS, SEXAFS, and XANES; Wiley: Chichester, 1988.

(34) Newville, M. J. Synchrotron Radiat. 2001, 8, 322-324.

(35) Ravel, B.; Newville, M. Phys. Scr. 2005, T115, 1007.

(36) te Velde, G.; Bickelhaupt, F. M.; Baerends, E. J.; Fonseca Guerra, C.; van Gisbergen, S. J. A.; Snijders, J. G.; Ziegler, T. J. Comput. Chem. 2001, 22, 931-967.

(37) Fonseca Guerra, C.; Snijders, J. G.; te Velde, G.; Baerends, E. J. Theor. Chem. Accounts Theory, Comput. Model. (Theoretica Chim. Acta) 1998, 99, 391-403.

(38) Ugliengo, P.; Sodupe, M.; Musso, F.; Bush, I. J.; Orlando, R.; Dovesi, R. Adv. Mater. 2008, 20, 4579-4583. 
(39) Perdew, J. P.; Burke, K.; Ernzerhof, M. Phys. Rev. Lett. 1996, 77, 3865-3868.

(40) Perdew, J. P.; Burke, K.; Ernzerhof, M. Phys. Rev. Lett. 1997, 78, 1396-1396.

(41) Grimme, S.; Antony, J.; Ehrlich, S.; Krieg, H. J. Chem. Phys. 2010, 132, 154104.

(42) van Lenthe, E.; Ehlers, A.; Baerends, E. J. J. Chem. Phys. 1999, $110,8943$.

(43) van Lenthe, E.; Baerends, E. J.; Snijders, J. G. J. Chem. Phys. 1994, 101, 9783.

(44) van Lenthe, E.; Baerends, E. J.; Snijders, J. G. J. Chem. Phys. 1993, 99, 4597.

(45) Klamt, A. J. Phys. Chem. 1995, 99, 2224-2235.

(46) Klamt, A.; Schüürmann, G. J. Chem. Soc., Perkin Trans. 2 1993, No. 5, 799-805.

(47) Riisager, A.; Fehrmann, R.; Flicker, S.; van Hal, R; Haumann, M.; Wasserscheid, P. Angew. Chem., Int. Ed. 2005, 44, 815-819.

(48) Zhang, Q.; Zhang, S.; Deng, Y. Green Chem. 2011, 13, 26192637.

(49) Zhao, D.; Feng, J.; Huo, Q.; Melosh, N.; Fredrickson, G. H.; Chmelka, B. F.; Stucky, G. D. Science 1998, 279, 548-552.

(50) Conley, M. P.; Copéret, C.; Thieuleux, C. ACS Catal. 2014, 4, $1458-1469$.

(51) Zagdoun, A.; Rossini, A. J.; Conley, M. P.; Grüning, W. R.; Schwarzwälder, M.; Lelli, M.; Franks, W. T.; Oschkinat, H.; Copéret, C.; Emsley, L.; Lesage, A. Angew. Chem., Int. Ed. 2013, 52, 1222-1225.

(52) Kubicki, D. J.; Rossini, A. J.; Purea, A.; Zagdoun, A.; Ouari, O.; Tordo, P.; Engelke, F.; Lesage, A.; Emsley, L. J. Am. Chem. Soc. 2014, 136, 15711-15718.

(53) Lesage, A.; Bardet, M.; Emsley, L. J. Am. Chem. Soc. 1999, 121, 10987-10993.

(54) Gullion, T.; Schaefer, J. J. Magn. Reson. 1989, 81, 196-200.

(55) Gullion, T. Concepts Magn. Reson. 1998, 10, 277-289. 